\title{
Efeito do número de ordenhas diárias sobre o desempenho reprodutivo de vacas mestiças Holandês-Zebu
}

\section{Effect of the number of daily milking on reproductive performance of crossbred (Holtein x Zebu) cows}

\author{
Felipe Zandonadi Brandão, ${ }^{\star}$ José Reinaldo Mendes Ruas, ${ }^{\star \star}$ José Monteiro da Silva Filho, ${ }^{\star \star \star}$ Alán Maia Borges, ${ }^{* \star \star}$ \\ Arismar de Castro Menezes, ${ }^{* * * *}$ Reginaldo Amaral, ${ }^{* *}$ Geraldo Francisco Chagas, ${ }^{* \star * *}$ Bruno Campos de Carvalho, ${ }^{* \star}$ \\ Jéferson Ferreira da Fonseca****
}

\begin{abstract}
Resumo
Avaliou-se a influência do número de ordenhas diárias sobre o desempenho reprodutivo de 63 vacas mestiças (HolandêsZebu) com boa condição corporal ao parto, distribuídas em três grupos (G) experimentais: Gl - vacas ordenhadas uma vez ao dia; GII - vacas ordenhadas duas vezes ao dia; GIII - vacas ordenhadas alternadamente a cada 14 dias, uma ou duas vezes ao dia. O retorno ao estro (84,3 dias; 81,7 dias e 71,2 dias); a taxa de manifestação de estro $(80,9 \% ; 80,90 \%$ e $80,90 \%)$; o período de serviço (99,0 dias; 114,0 dias e 93,1 dias) e a taxa de gestação até 120 dias pós-parto $(66,7 \% ; 57,1 \% ; 66,7 \%)$ não foram influenciados $(P>0,05)$ pelo aumento do número de ordenhas diárias.
\end{abstract}

Palavras-chave: Bos taurus $\mathrm{X}$ Bos indicus, número de ordenhas, características reprodutivas.

\begin{abstract}
This study was carried out to evaluate the influence of the number of daily milking on reproductive performance of 63 crossbred (Holstein-Zebu) cows, with good body condition score at calving, allocatted into three groups $(G)$ according the number of daily milking: GI - cows milked once a day; Gll - cows milked twice a day; Glll - cows milked alternating once or twice a day, every fourteen days. The return to estrous (84.3 days; 81.7 days and 71.2 days); estrous rates $(80.9 \% ; 80.90 \%$ e $80.90 \%$ ); service period (99.0 days; 114.0 days and 93.1 days) and pregnant rates until 120 day postpartum $(66.7 \% ; 57.1 \% ; 66.7 \%)$ were not influenced $(P>0.05)$ by the number of daily milking.
\end{abstract}

Keyword: Bos taurus X Bos indicus, number of milking, reproductive characteristics.

\section{Introdução}

Vacas ordenhadas três vezes ao dia tenderam a perder mais peso, quando comparadas às ordenhadas duas vezes ao dia, sugerindo maior catabolismo para manter a produção de leite. Além disso, observou-se que vacas ordenhadas três vezes ao dia apresentaram maior intervalo de partos (Barners et al., 1990).

O efeito da amamentação sobre a condição anovulatória da vaca é um dos grandes problemas presentes nos sistemas de produção de gado de corte e de animais de duplo propósito em todo o mundo (Short et al., 1990).

Acreditou-se que o estímulo sensorial intenso dos tetos (mamadas) fosse a principal causa de bloqueio da ovulação durante o período da lactação em todas as espécies. Entretanto, McVey e Williams (1991) utilizaram uma proteção de látex nos tetos das vacas na tentativa de inibir os efeitos da mamada sobre a reprodução, e os resultados mostraram que o uso dessa proteção de látex foi incapaz de reverter os efeitos negativos da amamentação. Os mesmos resultados foram observados por Viker et al. (1993) com a retirada cirúrgica da glândula mamária.

O vínculo entre a mãe e o bezerro é uma condição que resulta na ocorrência do processo de anovulação no pós-parto. Vacas de corte que amamentam bezerros de outras vacas por até seis dias apresentaram as mesmas alterações neuroendócrinas observadas no desmame, ou seja, um rápido aumento da freqüência dos pulsos de $\mathrm{LH}$, desenvolvimento de um folículo pré-ovulatório, ovulação e reinício da ciclicidade luteal ovariana (Silveira et al., 1993). A criação de um vínculo afetivo por parte da vaca, aliada à interação física do bezerro na região inguinal (cabeçadas, amamentação) são responsáveis, aparentemente, por alterações neuroendócri-nas que originam o estado anovulatório. Dentre essas mudanças, destacam-se o aumento da sensibilidade do hipotálamo ao feedback negativo do estrógeno e o aumento dos estímulos

\footnotetext{
* Professor do Departamento de Patologia e Clínica Veterinária da Faculdade de Veterinária da UFF - fzbr@vm.uff.br.

** Pesquisadores da EPAMIG.

*** Professor do Departamento de Clínica e Cirurgia da Escola de Veterinária da UFMG.

**** Técnico Agrícola - EPAMIG, Felixlândia, MG.

*****Pesquisador da Embrapa Caprinos - Núcleo Sudeste.
} 
dos peptídeos opióides endógenos que suprimem a secreção de GnRH e LH (Griffith e Williams, 1996).

A habilidade das vacas amamentando em desbloquearem a ação dos peptídeos opióides endógenos durante o início do pós-parto depende do nível de ingestão de energia e proteína a que estão submetidas neste período. Segundo Sinclair et al. (1995), vacas amamentando e recebendo dieta com altos teores de energia no início do pós-parto são submetidas por menor tempo à ação bloqueadora dos opióides endógenos sobre a secreção de LH. Assim, voltam a ciclar mais rapidamente, quando comparadas àquelas recebendo dietas com baixos teores de energia no início do pós-parto. Parece que a secreção de LH é inibida também por outros fatores que não os opióides endógenos e que as reservas de LH são influenciadas pela condição nutricional do animal.

Este experimento teve como objetivo estudar a influência do número de ordenhas diárias em vacas mestiças sobre as seguintes caracterísiticas: dias para retorno ao estro após o parto, período de serviço, taxa de gestação e manifestação do cio até 120 dias pós-parto.

\section{Material e métodos}

Foram utilizadas 63 vacas primíparas e multíparas mestiças (Holandês X Zebu), distribuídas ao acaso, no momento do parto, em três grupos experimentais com um número igual de repetições, correspondendo aos diferentes números de ordenhas diárias, a saber: grupo I - vacas ordenhadas uma vez ao dia; grupo II - vacas ordenhadas duas vezes ao dia e grupo III - vacas ordenhadas alternadamente, a cada 14 dias, uma vez e duas vezes ao dia. As vacas do grupo I foram ordenhadas uma vez ao dia a partir das seis horas da manhã, enquanto as do grupo II o foram duas vezes ao dia, às 6 e 14 horas. As do grupo III foram ordenhadas uma ou duas vezes ao dia de forma alternada: nos primeiros 14 dias após o parto, o foram duas vezes ao dia, nos 14 dias seguintes, uma vez ao dia, e assim se procedeu até o final da lactação. Os horários das ordenhas dos grupos II e III foram os mesmos.

Utilizaram-se 37 vacas mestiças primíparas e 26 multíparas de composições genéticas variada -51 animais $-1 / 2$ Holandês $X 1 / 2$ Zebu; 9 animais - 3/4 Holandês X $1 / 4$ Zebu e 3 animais - $1 / 4$ Holandês X $3 / 4$ Zebu - sendo as diferentes composições genéticas igualmente distribuídas entre os tratamentos.

As vacas foram mantidas em pastos de capim-braquiária (Brachiaria decumbens e Brachiaria brizantha). Receberam diariamente, no momento da ordenha, concentrado contendo $22 \%$ de proteína bruta e $75 \%$ de NDT, de acordo com a produção, fornecendo para cada $3 \mathrm{~kg}$ de leite produzidos, acima dos primeiros $8 \mathrm{~kg}$ de leite, $1 \mathrm{~kg}$ de concentrado. $\mathrm{Na}$ época da seca, os animais receberam silagem de milho (Zea mays, Z.) e/ou cana-de-açúcar ad libitum como fonte de volumoso. Vacas com menos de 90 dias pós-parto receberam apenas silagem de milho. Após esse período, somente as que apresentavam produção acima de $14 \mathrm{~kg}$ de leite diário receberam apenas silagem de milho. Vacas com produções entre 11 a $14 \mathrm{~kg}$ de leite por dia receberam $50 \%$ de silagem de milho e $50 \%$ de cana-de-açúcar, e as que produziram menos de $11 \mathrm{~kg}$ de leite apenas cana-de-açúcar acrescida de $1 \%$ de uréia. A quantidade de concentrado fornecido na estação da seca foi mantida na mesma relação anterior, porém, a partir dos primeiros $5 \mathrm{~kg}$ de leite produzidos.

O sistema de ordenha utilizado foi o mecânico, com o equipamento tipo balde ao pé em fosso, em linha dupla e com seis conjuntos de ordenha. Nos primeiros 90 dias após o parto, foi deixada um teto sem ser ordenhado para o bezerro; após esse período, a ordenha passou ser completa. A lactação foi encerrada quando após dois controles leiteiros consecutivos o animal produziu menos que $3 \mathrm{~kg}$ de leite, ou quando faltavam 60 dias para o próximo parto. O bezerro era levado à vaca para estimular a descida do leite, mas a ordenha acontecia na ausência do bezerro. As vacas foram pesadas no dia do parto e a cada 28 dias. As avaliações do escore corporal foram feitas nos dias das pesagens seguindo-se a escala de 3 a 5 pontos ( 3 - baixo e 5 - alto; Ruas, 1998). $O$ controle de leite realizou-se a cada sete dias da lactação.

Foram analisadas as variáveis condição e peso corporal (ao parto e ao primeiro cio) e as características reprodutivas: dias para o retorno ao estro após o parto, período de serviço, taxa de gestação e manifestação de cio até 120 dias pós-parto. As características reprodutivas foram avaliadas com base no dia da manifestação do estro após o parto e no número de animais gestantes após cobrições realizadas por touros em regime de monta natural de confirmada fertilidade.

Para a variável produção de leite aplicou-se à análise de variância. As médias foram comparadas pelo teste StudentNewman-Keuls. Para peso corporal ao parto e ao primeiro cio, características de controle, e para as variáveis escore corporal, dias para retorno ao estro e período de serviço foi utilizado o teste Kruskal-Wallis. Os dados proporcionais, taxas de manifestação de estro e gestação, foram submetidos ao teste de qui-quadrado (Snedcor e Cochran, 1980). Para o processamento das análises, utilizou-se o programa SAS (User's... 1986).

\section{Resultados e discussão}

$\mathrm{Na}$ Tabela 1 são apresentados os dados referentes ao peso e escore da condição corporal ao parto e ao primeiro cio dos animais. Não houve diferenças entre os grupos $(P>0,05)$. $O$ escore da condição corporal ao parto e ao primeiro cio seguem as recomendações entre 3,5 a 4,0 de Ferreira (1991). Roberts et al. (1997) afirmaram que vacas que pariram sob baixa condição corporal (<4 na escala de 1 a 9) apresentam maior concentração plasmática de $\mathrm{GH}$, menor concentração intrafoliculares do fator de crescimento semelhante à insulina (IGFI) e menor população de folículos médios e grandes nos ovários. Yavas e Walton (2000) mencionaram que vacas ao parirem em boa condição corporal apresentaram desenvolvimento folicular no início do período pós-parto, acompanhado por alta concentração circulante de IGF-I e maior freqüência de pulsos de LH. Sinclair et al. (1995) demonstraram que a concentração circulante de insulina no pós-parto correlacionou-se positivamente com a condição corporal. O escore da condição corporal ao parto, no presente experimento, não se constituiu em fator limitante para o retorno à atividade ovariana lútea cíclica (AOLC). Do parto ao dia do primeiro cio houve perda de peso e da condição corporal. 
Tabela 1: Médias do peso vivo $(\mathrm{kg})$ e escore da condição corporal ao parto e ao primeiro cio de vacas mestiças Holandês-Zebu submetidas a diferentes manejos de ordenha (média \pm desvio-padrão)

\begin{tabular}{lccc}
\hline Característica & $\begin{array}{c}\text { GI - uma ordenha } \\
\text { ao dia }\end{array}$ & $\begin{array}{c}\text { Gll - duas ordenhas } \\
\text { ao dia }\end{array}$ & $\begin{array}{c}\text { Glll - uma ou duas } \\
\text { ordenhas ao dia }\end{array}$ \\
\hline Peso ao parto $(\mathrm{kg})$ & $484,8 \pm 38,1^{\mathrm{Aa}}(21)$ & $496,4 \pm 67,9^{\mathrm{Aa}}(21)$ & $497,7 \pm 44,9^{\mathrm{Aa}}(21)$ \\
Peso no $1^{\circ}$ cio $(\mathrm{kg})$ & $456,9 \pm 31,2^{\mathrm{Ba}}(15)$ & $483,4 \pm 67,4^{\mathrm{Ba}}(17)$ & $464,0 \pm 47,5^{\mathrm{Ba}}(14)$ \\
\hline Escore corporal ao parto & $4,1 \pm 0,4^{\mathrm{Aa}}(21)$ & $3,7 \pm 0,4^{\mathrm{Aa}}(21)$ & $3,9 \pm 0,5^{\mathrm{Aa}}(21)$ \\
Escore corporal no $1^{\circ}$ cio & $3,6 \pm 0,3^{\mathrm{Ba}}(15)$ & $3,6 \pm 0,4^{\mathrm{Ba}}(17)$ & $3,5 \pm 0,3^{\mathrm{Ba}}(14)$ \\
\hline Produção diária de leite $(\mathrm{kg})$ & $7,4 \pm 1,6^{\mathrm{b}}(21)$ & $10,1 \pm 2,6^{\mathrm{a}}(21)$ & $9,7 \pm 2,0^{\mathrm{a}}(21)$ \\
\hline
\end{tabular}

Médias na mesma linha seguidas de letras minúsculas distintas diferem $(P<0,05)$ entre si pelo teste Kruskal-Wallis (peso vivo e escore corporal) ou pelo teste Student-Newman-Keuls (produção de leite).

Médias na mesma coluna seguidas de letras maiúsculas distintas diferem $(P<0,05)$ entre si pelo teste Kruskal-Wallis (peso vivo e escore corporal).

Valores entre parênteses referem-se ao número de animais em cada grupo experimental.
Segundo Short et al. (1990), a lactação compete com a reprodução por nutrientes, tendo maior importância na escala de prioridades no organismo animal. Dessa forma, diante do aumento na produção diária de leite, em decorrência do aumento do número de ordenhas diárias, deverá ser oferecida dieta em maior quantidade e melhor qualidade pois, caso contrário, poderá haver diferentes intensidades de mobilização das reservas corporais e A produção média diária de leite dos animais ordenhados uma vez ao dia foi menor $(P<0,05)$ quando comparada à dos demais grupos experimentais. $\mathrm{O}$ aumento do número de ordenhas determinou aumento na produção de leite, mas não implicou perdas de peso e do escore da condição corporal $(P>0,05)$. DePeters et al. (1985) aumentaram o número de ordenhas diárias e observaram que vacas ordenhadas três vezes ao dia perderam mais peso, quando comparadas às ordenhadas duas vezes ao dia, demonstrando maior demanda energética. Barnes et al. (1990) observaram que o aumento do número de ordenhas diárias levou à maior perda de peso das vacas, o que sugere maior catabolismo tecidual para manter o aumento da produção de leite, fato não observado neste trabalho. Isso pode ser explicado pela nutrição adequada oferecida aos animais no períododo pós-parto, ou devido à menor demanda de nutrientes em função da baixa produção de leite diária.

A dieta dos animais constituiu-se basicamente de pastagem de capim-braquiária na época das chuvas e de silagem de milho e cana-de-açúcar na época da seca. O concentrado foi ofertado individualmente de acordo com o nível produção de leite do animal, com maior disponibilidade na seca. Presumese, assim, que a dieta oferecida aos animais tenha sido de boa qualidade, de forma a não constituir em fator limitante para o retorno à AOLC.

$\mathrm{Na}$ Tabela 2 observa-se o intervalo (em dias) para o retorno à AOLC pós-parto, traduzidos pela manifestação do primeiro cio. $\mathrm{O}$ aumento do número de ordenhas diárias não alterou esse intervalo $(P>0,05)$, embora se sabe que vários fatores, como a produção de leite e a relação mãe e cria, possam ser responsabilizados pelo retorno à AOLC no pós-parto.

Tabela 2: Número de dias para o retorno ao cio pós-parto de vacas mestiças Holandês-Zebu submetidas a diferentes manejos de ordenha (média \pm desvio)

\begin{tabular}{lcc}
\hline Grupo $(\mathrm{G})$ & $\mathrm{n}$ & Média \pm desvio \\
\hline Gl - uma ordenha ao dia & 21 & $84,3 \pm 40,6$ \\
GII - duas ordenhas ao dia & 20 & $81,7 \pm 60,2$ \\
Glll- uma ou duas ordenhas ao dia & 21 & $71,2 \pm 44,2$ \\
\hline
\end{tabular}

até mesmo inibição da ingestão de alimentos com prejuízo no desempenho reprodutivo, caracterizado pelo aumento no tempo para o retorno à AOLC.

A relação da vaca com sua mãe e cria constitui-se em um fator regulador do retorno à AOLC no pós-parto, assumindo maior importância quando acompanhada por nutrição inadequada (Williams et al., 1993). Neste experimento, os bezerros tinham acesso às mães durante 30 minutos após o término de cada ordenha. Assim, as vacas do grupo II tiveram maior período de contato com seus bezerros, quando comparado com as do grupo I. Segundo Short et al. (1990), o efeito da amamentação sobre a condição anovulatória na vaca é um dos grandes problemas presentes nos sistemas que utilizam animais de duplo propósito. Acreditou-se, por muito tempo, ser o estímulo do bezerro na glândula mamária o fator desencadeador do anestro pós-parto. Contudo, experimentos realizados por Williams et al. (1993) não comprovaram essa teoria, pois o vínculo afetivo da vaca com sua cria, aliada à interação física do bezerro na região inguinal, é responsável por alterações neuroendócrinas que induzem ao estado anovulatório, possivelmente as mediadas pelo aumento dos peptídeos opióides endógenos que inibem a secreção do $\mathrm{GnRH}$. O aumento do contato diário do bezerro com a sua mãe não foi suficiente para interferir no retorno à AOLC.

Não foi verificada influência do número de ordenhas sobre a taxa de manifestação de cio até 120 dias pós-parto, onde em todos os grupos apresentaram $80,9 \%(17 / 21)$ dos animais manifestando cio.

Não houve diferença $(P>0,05)$ quanto ao período de serviço entre grupos (Tabela 3). Entretanto, apenas os animais dos grupos I e III foram capazes de atingir a meta de produção almejada de um bezerro/vaca/ano. Segundo Yavas e Waltson (2000), geralmente 30 a $50 \%$ das vacas no rebanho conseguem atingir esse objetivo.

Tabela 3: Período de serviço (dias) de vacas mestiças Holandês-Zebu submetidas a diferentes manejos de ordenha

\begin{tabular}{lcc}
\hline Grupo $(\mathrm{G})$ & $\mathrm{n}$ & média \pm desvio \\
\hline GI - uma ordenha & 21 & $99,0 \pm 45,6$ \\
Gll - duas ordenhas & 20 & $114,0 \pm 63,1$ \\
GIII - uma ou duas ordenhas & 21 & $93,1 \pm 61,1$ \\
\hline
\end{tabular}


A utilização alternada de uma ou duas ordenhas diárias a cada 14 dias, durante a lactação, encurtou o período de serviço em 21 dias, correspondendo a um ciclo estral. Partindo-se da premissa de que a gestação dura cerca de 280 dias, restariam apenas 85 dias após o parto para a vaca tornar-se novamente gestante. Entretanto, há que se considerar um período de duas semanas no pós-parto para que os estoques de LH fossem repostos (Nett, 1987). Assim, restariam 64 dias para a vaca tornar-se gestante, o que representaria três ciclos estrais, implicando dizer que a ocorrência de mais um ciclo estral poderia ser de grande importância para o alcance da meta de uma gestação por ano. Segundo Galina et al. (2001), a utilização de manejos de mamadas minimiza o efeito bezerro sobre o retorno da AOLC. Para Silveira et al. (1993), vacas que amamentaram bezerros de outras vacas apresentaram as mesmas alterações neuroendócrinas observadas em animais desmamados, ou seja, o rápido aumento dos pulsos de $\mathrm{LH}$, associado ao desenvolvimento folicular.

Amos et al. (1983) não observaram efeito do aumento do número de ordenhas diárias sobre o período de serviço e verificaram que a adoção de uma ordenha diária a mais aumentou em 18 dias o período de serviço, com pequeno aumento no intervalo do parto e o primeiro estro (5,7 dias). DePeters et al. (1985), ao adotarem a terceira ordenha diária, observaram que o intervalo de partos aumentou em 30 dias (13 meses vs. 12 meses).

O aumento do número de ordenhas diárias não influenciou $(P>0,05)$ o desempenho reprodutivo dos animais dos diferentes grupos experimentais (Tab. 4). A taxa de gestação avaliada até os 120 dias pós-parto não foi influenciada pelos tratamentos realizados.

Tabela 4: Taxa de gestação efetiva até 120 dias pós-parto em vacas mestiças Holandês-Zebu, submetidas a diferentes manejos de ordenha

\begin{tabular}{|c|c|}
\hline Grupo $(G)$ & $\begin{array}{c}\% \text { (animais gestantes/total } \\
\text { de animais) }\end{array}$ \\
\hline GI - uma ordenha & $66,7 \%(14 / 21)$ \\
\hline Gll - duas ordenhas & $57,1 \%(12 / 21)$ \\
\hline GIII - uma ou duas ordenhas & $66,7 \%(14 / 21)$ \\
\hline
\end{tabular}

\section{Conclusões}

Pode-se concluir que o aumento do número de ordenhas diárias em vacas mestiças com boa condição corporal ao parto não influencia as características reprodutivas.

\section{Agradecimentos}

Os autores agradecem a parceria entre a EPAMIG e a Escola de Veterinária da UFMG que permitiu a execução deste trabalho, e à FAPEMIG pelo financiamento deste projeto.

\section{Referências}

AMOS, H. E.; KISER, T.; LOEWENSTEIN, M. Influence of milking frequency on productive and reproductive efficiencies of dairy cows. J. Dairy Sci., v. 68, p. 732-739, 1985.

BARNES, M. A.; PEARSON, R. E.; LUKES-WILSON, A. J. Effects of milking frequency and selection for milk yield on productive efficiency of Holstein cows. J. Dairy Sci., v. 73, p. 1603-1611, 1990.

DePETERS, E. J.;SMITH, N. E. ACEDO-RICO, J. Three or two times daily milking of older cows and first lactation cows for entire lactations. $J$. Dairy Sci., v. 68, p.123-132, 1985.

ERDMAN, R. A.; VARNER, M. Fixed yield responses to increased milking frequency. J. Dairy Sci., v. 78, p.1999-2003, 1995.

FERREIRA, A. M. Manejo reprodutivo e eficiência da atividade leiteira. Coronel Pacheco: Embrapa-CNPGL, 1991, 47 p. (Embrapa-CNPGL. Documentos, 46).

GALINA, C.S.; RUBIO, I.; BASURTO, $\mathrm{H}$. et al. Consequences of different suckling systems for reproductive activity and productivity of cattle in tropical conditions. Appl. An. Beh. Sci., v. 72, p. 255-262, 2001.

GRIFFITH, M. K.; WILLIAMS, G. L. Roles of maternal vision and olfaction in suckling-mediated inhibition of luteinizing hormone secretion, expression of maternal selectivity, and lactational performance of beef cows. Biol. Reprod., v. 54, p. 761-768, 1996.

MCVEY, W. R.; WILLIAMS, G. L. Mechanical masking of neurosensory pathways at the calf-teat interface: endocrine, reproductive and lactational features of the suckledanestrous cow. Theriogenology, v. 35, p. 931-941, 1991.

NETT, T. M. Function of the hypothalamic-hypophysial axis during the post-partum period in ewes and cows. J. Reprod. Fert., v. 34, suppl., p. 201-213, 1987.
ROBERTS, A. J.; NUGENT, R. A.; KLIND, J. et al. Circulating insulin-like growth factor I, insulin-like growth factor binding proteins, growth hormone, and resumption of estrus in postpartum cows subjected to dietary energy restriction. J. Anim. Sci., v. 75, p. 1909-1917, 1997.

RUAS, J. R. M. Eficiência reprodutiva e perfil metabólico de vacas zebu em relação a status reprodutivo, condição corporal, amamentação diferenciada e suplementação alimentar. 1998. 107 f. Tese (Doutorado em Zootecnia) - Universidade de Federal de Viçosa, Viçosa, MG.

SHORT, R. E.; BELLOWS, R. A.; STAIGMILLER, R. B. et al. Phisiological mechanisms controlling anestrus and infertility in postpartum beef cattle. J. Anim. Sci., v. 68, p.799-816, 1990.

SILVEIRA, P. A.; SPOON, R. A.; RYAN, D. P. et al. Evidence for maternal behavior as a requesite link in suckling-mediated anovulation in cows. Biol. Reprod., v. 49, p. 1338-1346, 1993.

SINCLAIR, K. D.; BROADBENT, P. J.; HUTCHINSON, J. S. M. Naloxone evokes a nutritionally dependent $\mathrm{LH}$ response in post partum beef cows but not in mid-luteal phase maiden heifers. Anim. Sci., v. 61, p. 219-230, 1995.

SNEDCOR, G. W.; COCHRAN, W. G. Statistical methods. Ames: lowa State Universty, $1980.505 \mathrm{p}$.

User's guide, 6.12 ed. SAS Institute, Cary, NC: SAS Institute. 1996.

VIKER, S. D.; LARSON, R. L.; KIRACOFE, G. H.; et al. Prolonged postpatum anovulation in mastectomized cows requires tactile stimulation by the calf. J. Anim. Sci., v. 71, p. 999-1003, 1993.

WILLIAMS, G. L.; MCVEY Jr., W. R.; HUNTER, J. F. Mammary somatosensory pathways are not required for suckling-mediated inhibition of luteinizing hormone secretion and delay of ovulation in cows. Biol. Reprod., v. 49, p. 1328-1337, 1993.

YAVAS, Y.; WALTON, J. S. Postpartum acyclicity in suckled beef cows: a review. Theriogenology, v. 54, p. 25-55, 2000. 